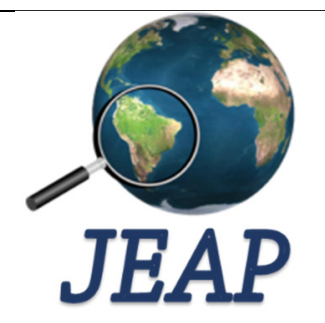

ISSN: 2525-815X

\section{Journal of Environmental} Analysis and Progress

Journal homepage: www.ufrpe.br/jeap http://dx.doi.org/10.24221/jeap.1.1.2016.985.70-83

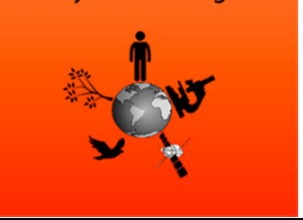

\title{
Sensibilidade do modelo SiSPAT em área de brejo de altitude no Nordeste do Brasil
}

\section{Sensitivity of SiSPAT model in the mountaineous area in the northeast of Brazil}

Willames de Albuquerque Soares ${ }^{\mathrm{a}}$, Antônio Celso Dantas Antonino ${ }^{\mathrm{b}}$, José Romualdo Sousa Lima ${ }^{\mathrm{c}}$, Manuella Virginia Salgueiro Gondim ${ }^{\mathrm{b}}$, Valmir Felix de Lima ${ }^{\mathrm{b}}$, Rodolfo Marcondes Silva Souza ${ }^{\mathrm{b}}$, Edevaldo Miguel Alves ${ }^{\mathrm{d}}$, Artur Paiva Coutinho ${ }^{\mathrm{d}}$

${ }^{a}$ Universidade de Pernambuco-UPE, Escola Politécnica de Pernambuco, Rua Benfica, 455, Madalena, Recife-PE, Brasil. CEP: 50720-001. E-mail: was@ poli.br.

b Universidade Federal de Pernambuco-UFPE, Departmento de Energia Nuclear-DEN, Av. Prof. Moraes Rego, 1235, Cidade Universitária, Recife-PE, Brasil. CEP: 50670-901. E-mail: acda@ufpe.br, manuellavirginia@yahoo.com.br, atrazina@gmail.com, rodolfo.marcondes@ufpe.br.

${ }^{c}$ Universidade Federal Rural de Pernambuco-UFRPE, Unidade Acadêmica de Garanhuns-UAG, Av. Bom Pastor, s/n, Boa Vista, Garanhuns-PE, Brasil. CEP: 55292-270. E-mail: romualdo.lima@ufrpe.br.

${ }^{\mathrm{d}}$ Centro Acadêmico do Agreste, UFPE. Rodovia BR-104, Km 59, s/n, Nova Caruaru, Caruaru-PE. CEP: 55002-970. Email: edevaldofisica@gmail.com, arthur.coutinho@yahoo.com.br.

\section{A R T I C L E I N F O}

Recebido 28 Sep 2016

Aceito 30 Sep 2016

Publicado 13 Oct 2016

\begin{abstract}
A B S T R A C T
Understand and quantify the water and energy changes are important for by the way meteorological, tillage and hydrologic. Numerous and complex are the process biophysical involved in the changes, difficult her measurement direct in big area, de form continuum e in the range of time, for that reason the big numerous de suit involved. So those developments Soil-Plant-Atmosphere Transfer model (SVAT) for explain the heat and mass changes. The Simple Soil-Plant-Atmosphere Transfer model (SiSPAT) is one that model. It application in the condition environment of the Europe. This study aim determining a sensibility of the SiSPAT model the eight parameter of the vegetation and four the soil. The components of the energy balance and the storage evapotranspiration utilized how parameter response. The area leaf index is the parameter of the vegetation the more influent. The model is more sensible at parameter of the soil.
\end{abstract}

Keywords: Energy balance, soil moisture, evapotranspiration.

\section{R E S U M O}

Compreender e quantificar as trocas de água e de energia são importantes para propósitos meteorológicos, agronômicos e hidrológicos. Os processos biofísicos envolvidos nessas trocas são numerosos e complexos, dificultando sua medição direta em grandes áreas, de forma contínua e num grande intervalo de tempo, devido ao grande número de equipamentos e recursos envolvidos. Desse modo, foram concebidos modelos que descrevem essas trocas de massa e de calor no sistema SoloVegetação-Atmosfera, os chamados modelos SVATs. O Simple Soil-PlantAtmosphere Transfer (SiSPAT) é um desses modelos e o mesmo foi muito utilizado nas condições ambientais da Europa. Assim sendo, este trabalho teve como objetivo determinar a sensibilidade do modelo SiSPAT a oito parâmetros relativos a vegetação, para uma cultura de mamona, e a 4 parâmetros relativos à caracterização hídrica do solo. Os componentes do balanço de energia e a evapotranspiração 
acumulada foram utilizados como dados de resposta. Dentre os parâmetros da vegetação o índice de área foliar foi o que apresentou maior influência nos valores calculados pelo modelo SiSPAT. O modelo mostrou-se mais sensível as variações nos parâmetros relativos ao solo, sendo o parâmetro n o de maior influência. O fluxo de calor sensível foi o dado de saída analisado mais sensível.

Palavras-Chave: Balanço de energia, umidade do solo, evapotranspiração.

\section{Introdução}

A confiabilidade dos modelos utilizados em previsões meteorológicas, agronômicas ou hidrológicas está ligada a uma adequada representação do balanço de água e de energia nos modelos denominados Soil Vegetation Atmosphere Transfer (SVAT). Esses modelos necessitam da especificação de muitas propriedades do sistema, que geralmente são obtidas em laboratório e/ou de experimentos de campo. A precisão exigida para as propriedades do sistema depende do modelo e de sua complexidade. Pequenas imprecisões nas propriedades do sistema podem afetar significativamente o desempenho do modelo.

Os modelos SVAT necessitam de uma grande quantidade de parâmetros de entrada e condições iniciais que apresentam distribuição espacial e temporal. Em geral, quanto maior a complexidade do modelo, maior será a quantidade de parâmetros. Por exemplo, o modelo BiosphereAtmosphere Transfer Scheme (BATS) (Dickinson et al., 1993; Pereira et al., 2010; Neves et al., 2011) necessita de 27 parâmetros, dos quais 16 relacionados à vegetação e oito ao solo, além da umidade inicial. Por outro lado, o modelo Simple Soil-Plant-Atmosphere Transfers (SiSPAT) baseado em processos físicos, tais como as trocas acopladas de calor e água (líquida e vapor) no solo (Braud et al., 1995; Braud et al., 2013; Soares et al., 2013, Amazonas et al., 2015). Esse modelo necessita da especificação de cerca de 60 parâmetros (número dependente da descrição do solo). A maioria deles varia no tempo e no espaço e muitas vezes são obtidos por meio de experimentos in situ. As especificações dessas propriedades afetam significativamente 0 comportamento do modelo, fazendo-se necessário a sua calibração.

Alguns desses parâmetros não são medidos diretamente e nem se consegue determiná-los indiretamente com muita precisão, então um intervalo de valores é utilizado para representar o parâmetro. Se os valores de uma dada variável de saída não se mostram sensíveis às variações dentro destes limites, será razoável utilizar algumas estimativas nominais (como pontos médios). No entanto, se os resultados se mostrarem sensíveis, torna-se necessário determinar a melhor especificação destes parâmetros. O recurso mais utilizado é a calibração, condicionada à resposta de alguma variável medida disponível. É importante, portanto, identificar quais das variáveis de saída são sensíveis aos parâmetros de entrada do modelo (Silva et al., 2014).

Geralmente, uma calibração em modelos computacionais é considerada como a determinação de um conjunto de parâmetros ótimos, estabelecendo as melhores simulações de algumas variáveis (Silva et al., 2014).

Devido a erros na estrutura dos modelos e/ou de incertezas nos parâmetros de entrada, a determinação deste conjunto é muitas vezes impossível. Para reduzir os efeitos dos erros inerentes às incertezas dos dados de entrada, que depende da região e da cultura a ser modelada, são necessárias investigações da sensibilidade do modelo, que é uma ferramenta que permite concentrar os esforços experimentais nos parâmetros mais importantes (Bormann, 2008).

Uma análise de sensibilidade pode ser feita por três diferentes métodos: o analítico, o direto, também conhecido como construção da superfície de resposta, e o perturbativo diferencial. No método analítico, o coeficiente de sensibilidade é calculado pela derivação da solução analítica, quando existir, em relação ao parâmetro de interesse. No método direto executa-se o código, cujo modelo contém o sistema direto, tantas vezes quantas perturbações dos parâmetros sejam necessárias estudar. No método perturbativo diferencial formulam-se um sistema de equações que fornece a solução das variáveis e um sistema de equações derivado e seu correspondente sistema de equações adjunto, que fornecerá a solução das variáveis adjuntas. Depois se obtêm os coeficientes de sensibilidade por meio de operações envolvendo as soluções direta e adjunta (Soares 2009). A principal vantagem dos métodos perturbativos é a obtenção das sensibilidades desejadas com relação às variações dos parâmetros com apenas uma execução do código direto e uma execução de um código adjunto (Castrillo et al., 2004).

Vários estudos de sensibilidade de parâmetros utilizando modelos SVAT foram realizados. Xue et al. (1996) aplicaram o modelo Simplified Simple Biosphere model (SSiB), utilizando dados meteorológicos obtidos na floresta Amazônica durante o projeto ABRACOS (Anglo-Brazilian Amazonian Climate Observation Study) e observaram que os parâmetros mais significativos foram o índice de área de foliar e caracterização hidrodinâmica do solo. Kahan et al. 
(2006) avaliaram o modelo $\mathrm{SSiB}$ na caatinga africana e concluíram que os parâmetros que mais afetam a simulação da evaporação, e conseqüentemente o balanço hídrico, são: o índice de área foliar, a resistência estomática, e a condutividade hidráulica saturada. Além desses, eles observaram que a difusividade térmica possui uma influência muito forte sobre o fluxo de calor sensível e as variações de temperatura e, ainda, sugerem que para reduzir os erros deve ser feita uma calibração dos parâmetros relativos à vegetação e ao solo. Cunha (2007) aplicou o modelo $\mathrm{SSiB}$, para uma região de caatinga, no município de Petrolina-PE. Os parâmetros analisados foram: o índice de área foliar, a fração de folhas verdes, a fração de cobertura vegetal, o deslocamento do plano zero e o comprimento de rugosidade. Os efeitos desses parâmetros no saldo de radiação e no fluxo de calor no solo foram pequenos. As maiores influências desses parâmetros foram nos fluxos de calor sensível e latente.

Braud (1998) analisou a sensibilidade do escoamento superficial, da evapotranspiração, da evaporação do solo descoberto, da transpiração e da umidade do solo, em escala do campo, modeladas pelo SiSPAT, para dados obtidos numa Savana Africana durante o projeto HAPEX-Sahel em 1992, por um período de 18 dias. Primeiramente o modelo foi calibrado, utilizando uma série de dados, que forneceram um conjunto de referência dos parâmetros. Ela observou que os processos mais sensíveis, com relação a caracterização hidronâmica do solo, foram: o escoamento superficial, o fluxo de calor latente e principalmente a evaporação do solo descoberto; que o índice de área foliar foi o fator que mais influenciou a modelagem da transpiração, mesmo com uma vegetação muito escassa, e que a distribuição de água no solo é muito sensível à especificação de parâmetros do solo, como a pressão de borbulhamento, o parâmetro $\mathrm{n}$, a condutividade hidráulica saturada e o parâmetro $\eta$. Ela conclui ainda que para modelos em geral, que utilizam a equação de Richards como base deve ser usada com cuidado em regiões de grandes escalas. Boulet et al (1999) avaliaram a influência da variabilidade espacial dos parâmetros do solo, em escala regional, utilizando o modelo SiSPAT, para dados obtidos da estação em Lockyersleigh (Austrália). Eles observaram que o escoamento superficial é muito sensível aos parâmetros do solo e é insensível aos parâmetros da vegetação; que a evaporação do solo é muito sensível ao expoente da curva de Van Genuchten (1980), de retenção de água no solo, a profundidade da camada inicial, ao índice de área foliar, ao parâmetro de escala n, a umidade volumétrica saturada e a resistência estomática mínima, por ordem; que a transpiração é mais sensível à resistência estomática mínima do que as variações do parâmetro de escala.

Desta forma, o objetivo deste estudo foi determinar a sensibilidade da evapotranspiração acumulada e dos componentes do balanço de energia, simulados pelo modelo SiSPAT a 8 parâmetros relativos à vegetação e a 4 parâmetros relativos as características hidrodinâmicas do solo.

\section{Material e Métodos}

O modelo SiSPAT (Simple Soil-PlantAtmosphere Transfers) descreve as trocas verticais de calor e água no sistema solo-planta-atmosfera. Basicamente, o SiSPAT é um modelo unidimensional (vertical), forçado com séries climáticas de temperatura e umidade do ar, velocidade do vento, radiação global e atmosférica e precipitação pluviométrica. O modelo é dividido esquematicamente em quatro módulos: o módulo solo, o módulo atmosfera, o módulo interface soloplanta-atmosfera e o módulo solo-planta (Antonino, 1992; Braud et al., 1995a). Uma descrição detalhada da versão do modelo SiSPAT usada neste trabalho pode ser encontrada em Braud (2000). A seguir será feita uma descrição resumida do modelo apresentando seus diferentes módulos.

No solo, o movimento vertical das trocas de calor e água é calculado por um sistema de duas equações não lineares acopladas, nas quais as variáveis dependentes são a temperatura e o potencial matricial do solo (Passerat de Silans et al., 1989; Antonino, 1992). As equações são resolvidas utilizando o método das diferenças finitas com esquema implícito (Celia et al., 1990). Os perfis de temperatura e de potencial matricial são utilizados como condição inicial, a temperatura e o potencial matricial do solo na base do perfil são utilizados como condição de fronteira inferior enquanto que as condições atmosféricas impõem as condições de fronteira superior.

As variáveis atmosféricas características são definidas em um nível de referência, caracterizada pela temperatura e umidade específica do ar e pela velocidade do vento. A estratificação térmica da atmosfera é considerada por meio da teoria de Monin \& Obukhov (1954) e as funções de correções da estabilidade atmosféricas são as de Paulson (1970). Assume-se que os coeficientes de rugosidade para calor e vapor são iguais, bem como as correspondentes funções integradas de estabilidade.

A modelagem da extração de água pelas raízes utilizada pelo modelo, é a proposta por Federer (1979), em que a circulação da água do solo para as raízes é função de duas resistências, a 
resistência da camada de solo que é considerada inversamente proporcional a sua condutividade hidráulica; e a resistência das raízes da planta na camada de solo que é obtida pela razão entre a resistência total da planta e a quantidade de camadas. Os movimentos de água do solo para a planta são induzidos por diferenças de potencial entre o solo e as folhas. A transpiração é considerada igual à extração de água pelas raízes. $\mathrm{O}$ perfil de densidade das raízes é descrito em função das profundidades: i) na qual a densidade de raízes é mínima, ii) na qual a densidade de raízes é máxima, e iii) máxima das raízes; e por um parâmetro que reflete a porcentagem máxima da densidade das raízes.

$\mathrm{Na}$ modelagem da interface Solo-PlantaAtmosfera as temperaturas do solo e do dossel arbóreo, e os fluxos de massa e de calor entre o solo, a vegetação e a atmosfera são calculados considerando a vegetação em uma única camada, e dois balanços de energia são efetuados, um para o solo sem vegetação e o outro para o solo vegetado. Para este fim, a radiação é dividida, utilizando um fator de partição, definido por Deardoff (1978), que é calculado em função do índice de área foliar. A partição do fluxo de momento entre o solo e o dossel também é função do IAF, de modo que os fluxos de momento são expressos em termos da resistência aerodinâmica, que controla a transferência de momento entre a superfície do solo e o ar dentro do dossel. Já a resistência estomática é modelada em função da radiação global e da água disponível para o sistema radicular.

\section{Sensibilidade do modelo}

Como o modelo SiSPAT utiliza pouco tempo em cada simulação, foi empregado o método de superfícies de resposta, isto é, cada parâmetro selecionado foi modificado para cada simulação, enquanto os demais foram mantidos constantes. $\mathrm{O}$ mesmo procedimento foi repetido para outro parâmetro e assim sucessivamente. Após cada simulação, analisaram-se as respostas que cada alteração, em cada parâmetro, ocasionou nos dados de saída. Os dados de saída avaliados foram a evapotranspiração acumulada (Evp), o saldo de radiação (Rn), e os fluxos de calor latente (LE), sensível $(\mathrm{H})$ e no solo $(\mathrm{G})$.

$O$ estudo de sensibilidade foi realizado considerando dados correspondendo a uma cultura de mamona (Ricinus communis) que se encontrava na fase de enchimento das bagas, a altura aproximadamente de $125 \mathrm{~cm}$, com um solo coberto pela vegetação.

Os dados de entrada do modelo SiSPAT analisados neste trabalho foram o índice de área foliar (IAF), as resistências estomática mínima
(Rsm), e máxima (RsM), o albedo ( $\alpha v)$ e a emissividade da vegetação (Ess), o potencial foliar crítico (PFC), a Resistência Total da Planta (RTP), o parâmetro "g" da função de estresse (g), a curva de retenção de água no solo, proposta por van Genuchten (1980), representada pela pressão de borbulhamento (hg) e pelo parâmetro de escala (n), além da condutividade hidráulica, proposta por Brooks \& Corey (1964), representada pela condutividade hidráulica saturada (Ks) e pelo

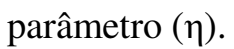

Foram empregadas variações, correspondentes a $\pm 20 \%$ e $\pm 10 \%$, nos parâmetros de entrada, a fim de perceber a sensibilidade do modelo a cada uma. As duas exceções foram o parâmetro n, da equação de van Genuchten, a Emissividade da vegetação. $\mathrm{O}$ parâmetro $\mathrm{n}$, da equação de van Genuchten, que, por hipótese, deve ser maior que 2 (Brooks \& Corey, 1964) teve variações correspondentes a $\pm 8 \% \mathrm{e} \pm 5 \%$. Como as variações de $\pm 20 \%$ e $\pm 10 \%$ no valor de referência da emissividade da vegetação $(0,96)$ implicariam em valores correspondentes impossíveis fisicamente, utilizou-se os valores $0,94(-2 \%), 0,95$ (-1\%), 0,97 (+1\%) E 0,98 (+2\%).

Os valores de referência e as respectivas variações, adotados para 12 parâmetros de entrada utilizados na análise de sensibilidade do modelo SiSPAT estão apresentados na Tabela 1.

\section{Resultados}

A evapotranspiração acumulada e o balanço de energia simulado pelo modelo SiSPAT, submetido as variações nos valores de referência do parâmetro $\mathrm{g}$ da função de estresse, do albedo e da emissividade da vegetação, não apresentaram sensibilidades.

Tanto a evapotranspiração como o balanço de energia não apresentaram sensibilidades significativas aos acréscimos do valor de referência do PFC. Para as reduções do valor de referência do PFC, o LE e o H calculados pelo SiSPAT se mostraram sensíveis, de forma bem discreta. Esta mesma falta de sensibilidade foi percebida nas variações da resistência total da planta (RTP).

Nenhum dos dados de saída aqui analisados se mostraram sensíveis as variações da RsM. Esta falta de sensibilidade dos modelos devese a disponibilidade hídrica utilizada na simulação, uma maior influência deveria acontecer caso a cultura estivesse sob um estresse hídrico. O modelo apresentou uma discreta sensibilidade para a Rsm, sendo no $\mathrm{H}$ a maior influência, sobretudo nos horários de pico. No horário de pico do quarto dia, o valor pontual do $\mathrm{H}$ foi de $202,66 \mathrm{~W} \cdot \mathrm{m}^{-2}$. Para as variações de $-20,-10,+10$ e $+20 \%$ no valor de referência, o modelo encontrou valore de pico para 
$\mathrm{H}$ de $177,02 \mathrm{~W} \cdot \mathrm{m}^{-2}(-12,38 \%), 188,96 \mathrm{~W} \cdot \mathrm{m}^{-2}$ ($6,43 \%), 214,02 \mathrm{~W} \cdot \mathrm{m}^{-2}(5,94 \%)$ e $223,92 \mathrm{~W} \cdot \mathrm{m}^{-2}$ $(10,89 \%)$.

As simulações das variáveis de saída analisadas, decorrentes das variações do IAF, não apresentaram grandes sensibilidades. $\mathrm{O}$ fluxo de calor sensível, a evapotranspiração acumulada e o saldo de radiação, não se apresentaram sensíveis as variações do Índice de Área Foliar (IAF). Os fluxos de calor latente (LE) e sensível (H) mostraram-se pouco sensíveis as variações IAF. Como pode ser vista nas Figuras 1 e 2, as reduções no valor de referência do IAF provocaram uma diminuição nos valores calculados pelo modelo SiSPAT para o LE e provocaram um aumento nos cálculos do H. De forma inversa, o aumento no valor de referência do IAF provocaram um aumento nos valores calculados de LE e uma diminuição nos valores calculados de $\mathrm{H}$.

Tabela 1. Dados de entrada relativos a cultura utilizados na análise de sensibilidade do modelo Simple SoilPlant-Atmosphere Transfers (SiSPAT).

\begin{tabular}{|c|c|c|c|c|c|}
\hline Parâmetro - Símbolo (Unidade) & Referência & $\begin{array}{l}\text { Ref - } \\
20 \%\end{array}$ & $\begin{array}{l}\text { Ref - } \\
10 \%\end{array}$ & $\begin{array}{l}\text { Ref + } \\
10 \%\end{array}$ & $\begin{array}{l}\text { Ref + } \\
20 \%\end{array}$ \\
\hline Índice de área foliar $-I A F$ & 1,15 & 0,92 & 1,04 & 1,27 & 1,38 \\
\hline $\begin{array}{l}\text { Resistência estomática mínima - Rsm } \\
(s / m)\end{array}$ & 120 & 96 & 108 & 132 & 144 \\
\hline $\begin{array}{l}\text { Resistência estomática máxima }-R s M \\
(s / m)\end{array}$ & 5380 & 4304 & 4842 & 5918 & 6456 \\
\hline Albedo vegetação - $\alpha v$ & 0,21 & 0,17 & 0,19 & 0,23 & 0,25 \\
\hline Emissividade da vegetação - $E s s^{\dagger}$ & 0,96 & 0,94 & 0,95 & 0,97 & 0,98 \\
\hline Potencial foliar crítico - PFC (m) & -80 & -90 & -110 & -120 & -80 \\
\hline $\begin{array}{l}\text { Resistência total da planta }-R T P(s / m) \\
\text { Parâmetro g da função de stress }-g\left(10^{-}\right.\end{array}$ & $3,00 \mathrm{E}+12$ & $2,4 \mathrm{E}+12$ & $2,7 \mathrm{E}+12$ & $3,3 \mathrm{E}+12$ & $3,6 \mathrm{E}+12$ \\
\hline$\left.{ }^{4} \mathrm{~Pa}^{-1}\right)$ & 2,50 & 2,00 & 2,25 & 2,75 & 3,00 \\
\hline Pressão de borbulhamento - $h g(m)$ & 0,03 & 0,024 & 0,027 & 0,033 & 0,036 \\
\hline Parâmetro $n^{*}$ & 2,18 & 1,74 & 1,96 & 2,40 & 2,62 \\
\hline $\begin{array}{l}\text { Condutividade hidráulica saturada }-K s- \\
(\mu \mathrm{m} / \mathrm{s})\end{array}$ & 9,50 & 7,60 & 8,55 & 10,5 & 11,4 \\
\hline Parâmetro $\eta$ & 11,23 & 8,98 & 10,11 & 12,35 & 13,48 \\
\hline
\end{tabular}

* Os valores correspondem a $-8 \%,-5 \%,+5 \%$ e $+8 \%$, respectivamente.

$\dagger$ Os valores correspondem a $-2 \%,-1 \%,+1 \%$ e $+2 \%$, respectivamente.

Estes resultados diferem do que foi apresentado por Braud (1998), que observou o IAF como sendo o parâmetro mais sensível do modelo SiSPAT. Entretanto vale ressaltar que a variável de saída analisada por esta autora foi a transpiração, variável esta que não foi analisada neste estudo. Os resultados também diferem dos encontrados por Cunha et al. (2007), que observaram uma grande influência do IAF no balanço de energia, simulado pelo modelo SSiB.

As variações nos valores da pressão de borbulhamento não afetaram significativamente os valores calculados pelo modelo SiSPAT para o saldo de radiação. Pouca sensibilidade foi observada pelo fluxo de calor no solo. O fluxo de calor latente mostrou-se mais sensível a reduções no valor de referência do hb. A maior sensibilidade foi encontrada nos cálculos dos fluxos de calor sensível, onde uma redução de $20 \%$ no valor de hb provocou um aumento nos valores calculados pelo SiSPAT de aproximadamente $100 \%$.

As variações nos valores da condutividade hidráulica saturada não afetaram significativamente os valores calculados pelo modelo SiSPAT para o Rn, LE e G. A sensibilidade observada nos valores da evapotranspiração foram insignificantes. Enquanto o valor final de referência foi de $30,5 \mathrm{~mm}$, os valores calculados foram de 29,13 $\mathrm{mm}(-20 \%), 29,86 \mathrm{~mm}(-10 \%)$, $31,13 \mathrm{~mm}(+10 \%)$ e de $31,63 \mathrm{~mm}(+20 \%)$. A maior sensibilidade foi encontrada nos cálculos dos fluxos de calor sensível, onde uma redução de 20 $\%$ no valor de Ks provocaram um aumento nos valores calculados pelo SiSPAT de aproximadamente $50 \%$ (Figura 5). As maiores variações aconteceram no horário da tarde do segundo dia, como pode ser visto no detalhe da Figura 6. 


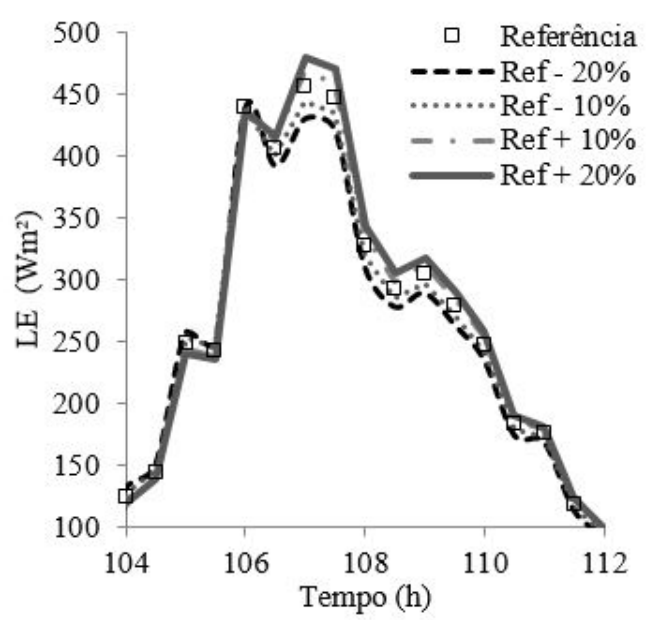

Figura 1. Detalhe da variação do fluxo de calor latente calculados a partir das variações do IAF.

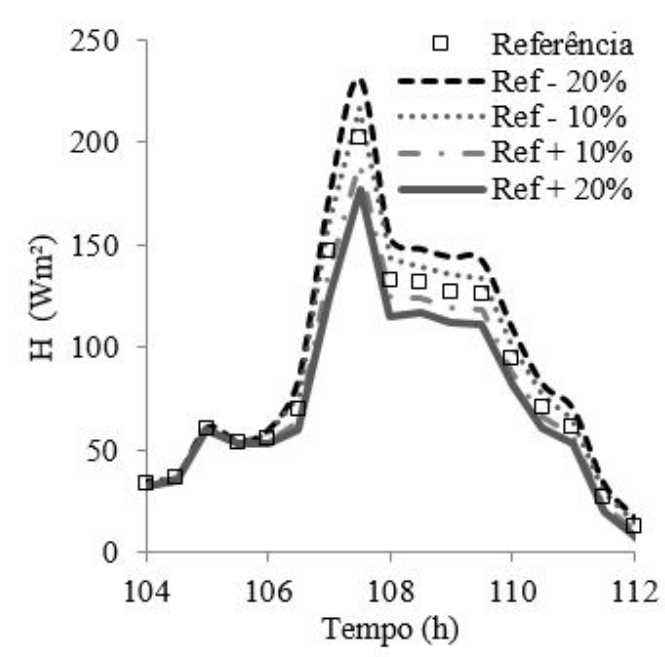

Figura 2. Detalhe da variação do fluxo de calor, calculados a partir das variações do IAF.

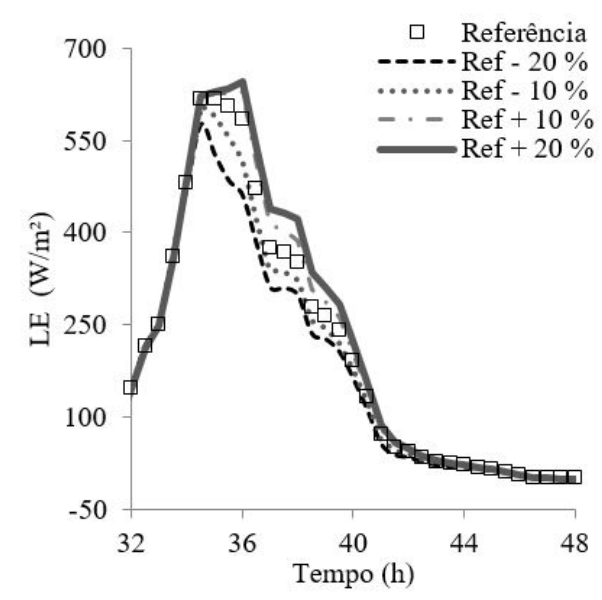

Figura 3. Detalhe da variação do fluxo de calor latente calculados a partir das variações do hg.

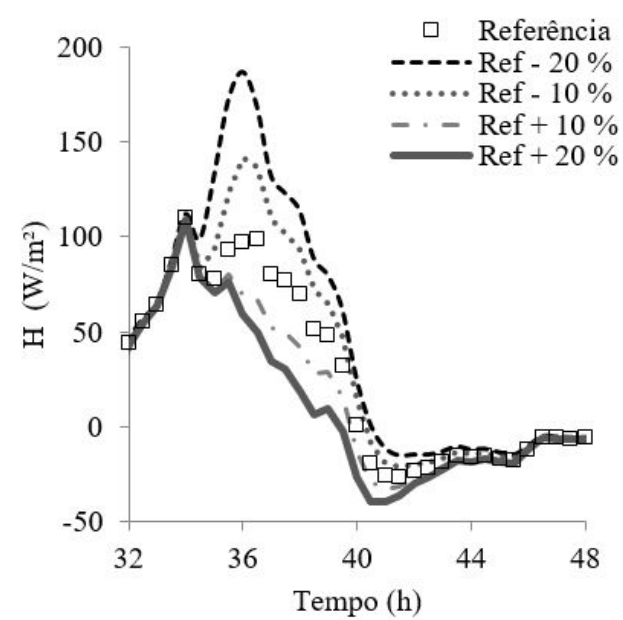

Figura 4. Detalhe da variação do fluxo de calor, calculados a partir das variações do hg.

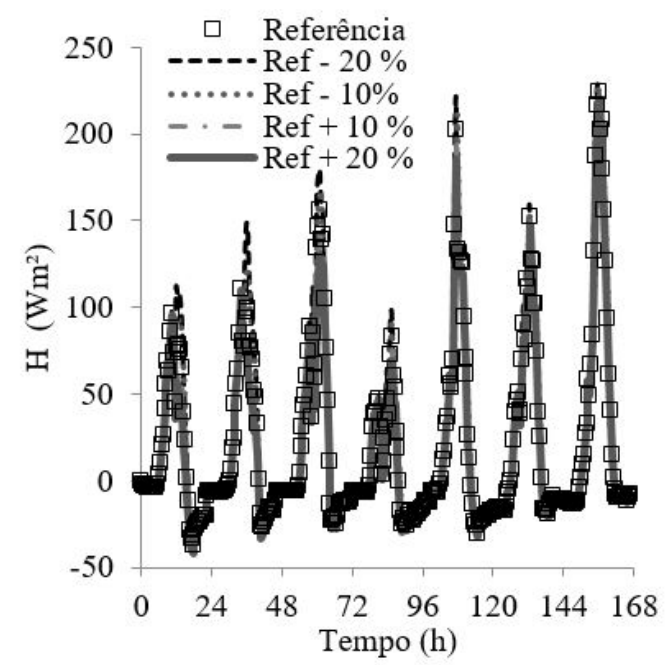

Figura 5. Variação do fluxo de calor sensível, calculados a partir das variações da Ks.

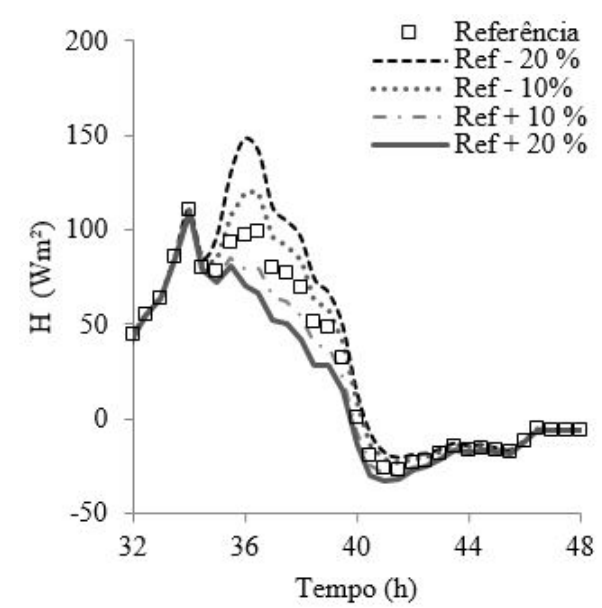

Figura 6. Detalhe da variação do fluxo de calor sensível, no segundo dia de simulação, calculados a parti das variações da Ks. 


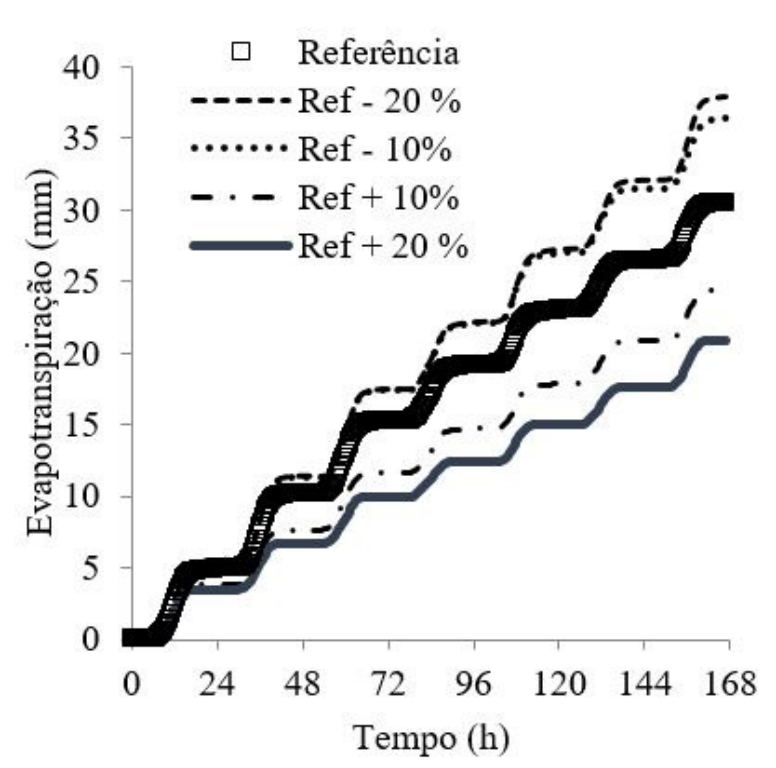

Figura 7. Variação da evapotranspiração acumulada, calculados a partir das variações do $\eta$.

O cálculo do fluxo de calor no solo apresentou certa sensibilidade as variações do parâmetro $\eta$, como pode ser visto na Figura 8.

Observa-se que as variações nos valores de referência do $\eta$ provocaram aumentos nos valores calculados, principalmente nos horários diurnos. No detalhe (Figura 9), observa-se que os aumentos nos valores de referência provocaram um aumento nos valores calculados.

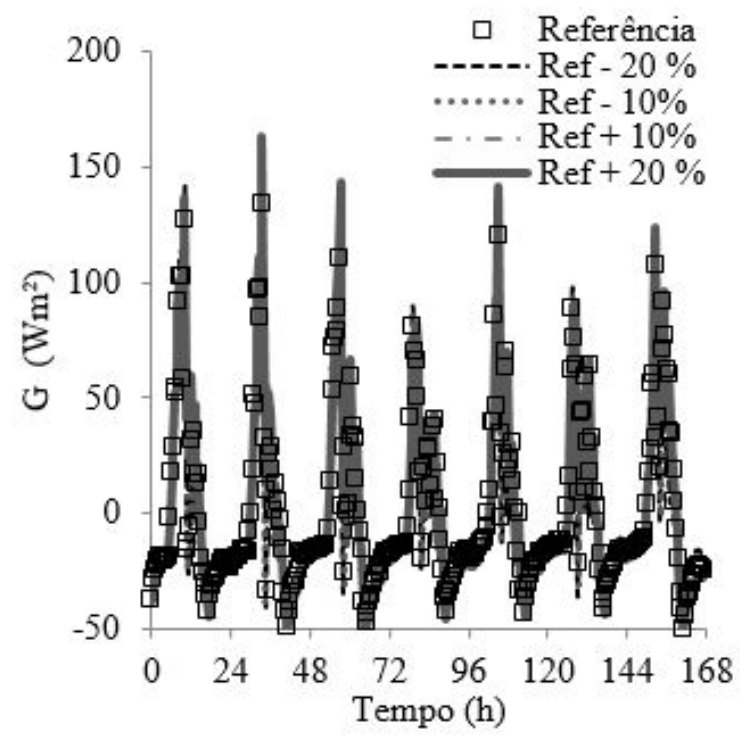

Figura 8. Variação do fluxo de calor no solo, calculados a partir das variações de $\eta$.

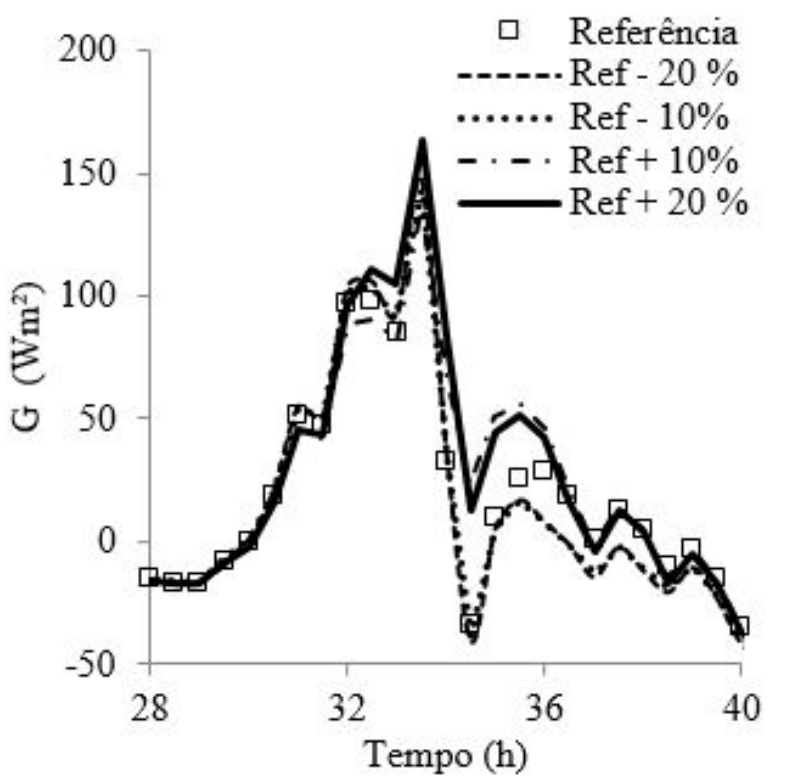

Figura 9. Detalhe da variação do fluxo de calor no solo, no segundo dia de simulação, calculados a parti das variações de $\eta$

O cálculo do fluxo de calor latente apresentou alta sensibilidade as variações do parâmetro $\eta$, como pode ser visto na Figura 10. Observa-se que as variações nos valores de referência do $\eta$ provocaram aumentos nos valores calculados, principalmente nos horários de pico. No detalhe (Figura 11), observa-se que os diminiução nos valores de referência provocaram um aumento da ordem de $200 \mathrm{~W} \cdot \mathrm{m}^{-2}$, cerca de 45 $\%$.

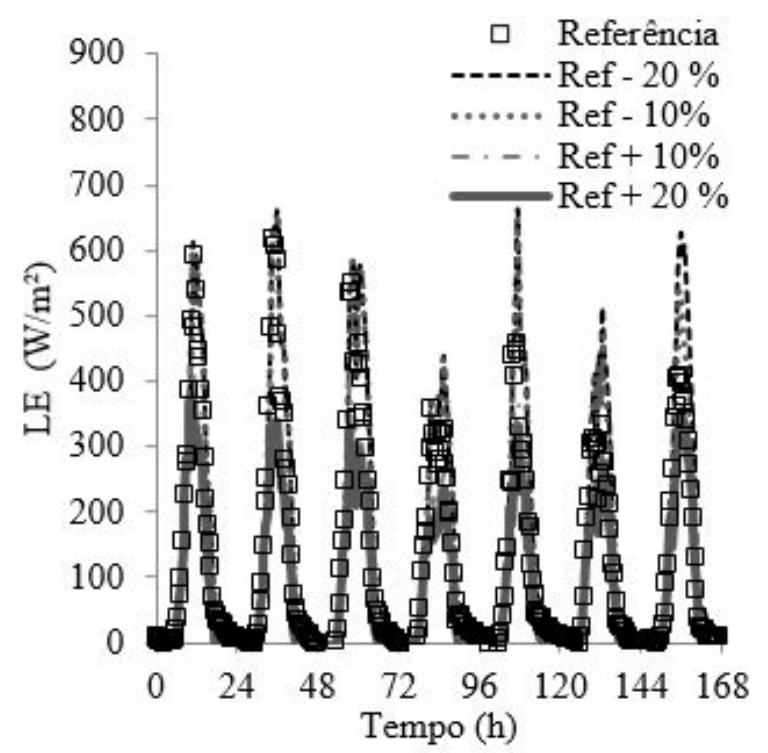

Figura 10. Evolução do fluxo de calor latente medido e calculados a partir das variações do $\eta$ 


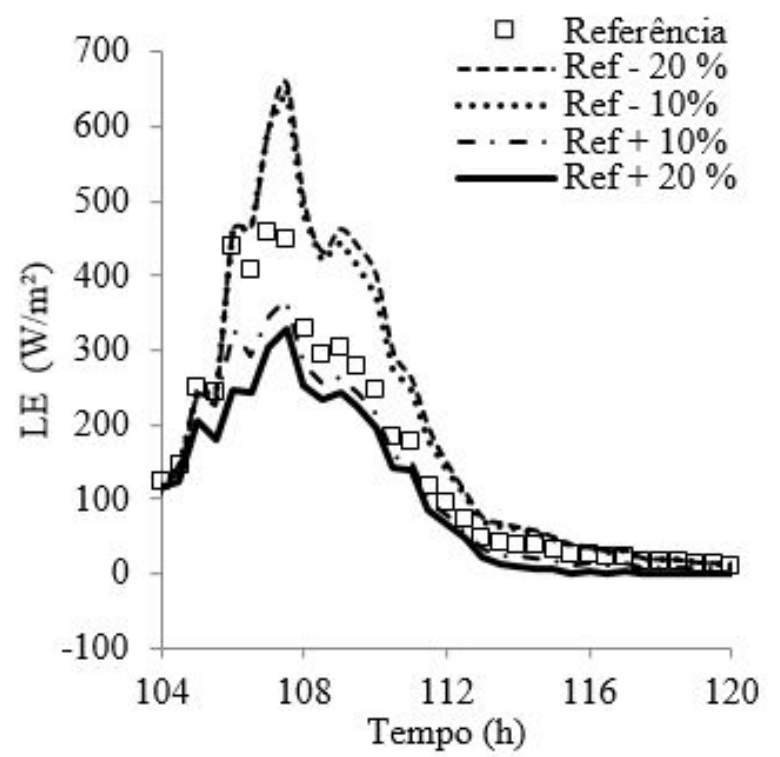

Figura 11. Detalhes da evolução do fluxo de calor latente medido e calculados a partir das variações do $\eta$.

O cálculo do fluxo de calor sensível apresentou grande sensibilidade as variações do parâmetro $\eta$, como pode ser visto na Figura 12. Observa-se que as variações nos valores de referência do $\eta$ provocaram aumentos nos valores calculados, principalmente nos horários de pico. No detalhe (Figura 13), observa-se que os aumentos nos valores de referência provocaram um aumento da ordem de $200 \mathrm{~W} . \mathrm{m}^{-2}$, cerca de $200 \%$.

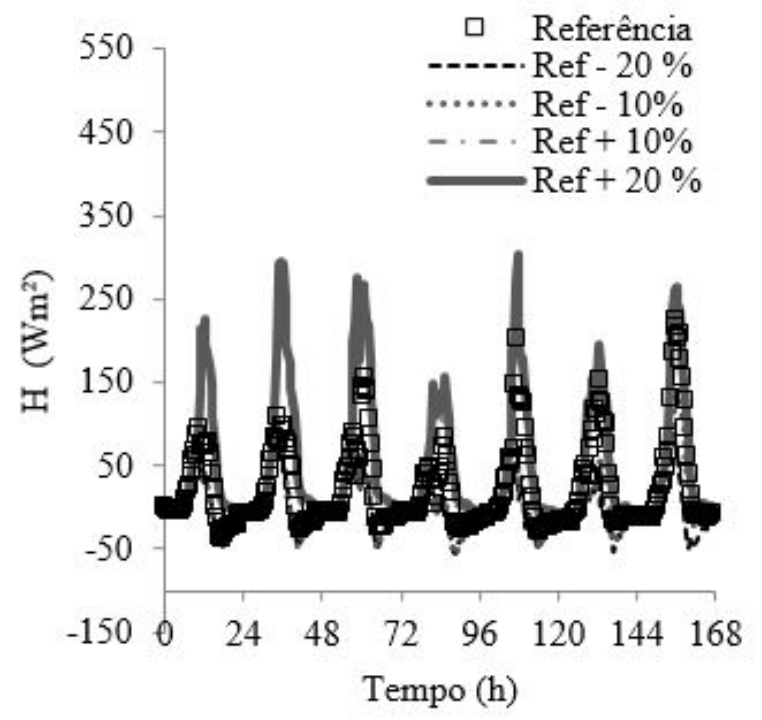

Figura 12. Evolução do fluxo de calor sensível medido e calculados a partir das variações do $\eta$.

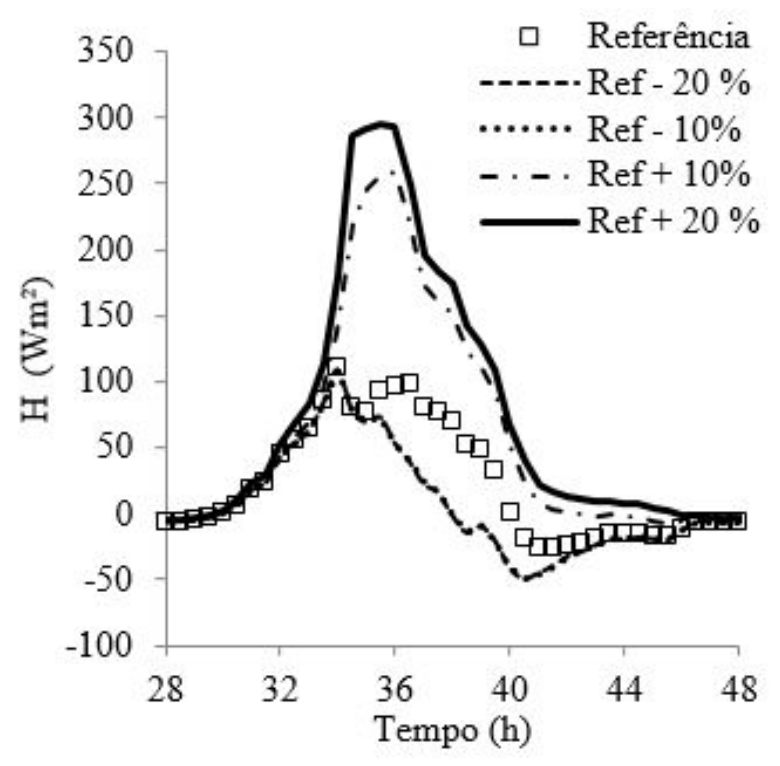

Figura 13. Detalhes da evolução do fluxo de calor sensível medido e calculados a partir das variações do $\eta$.

As variações no parâmetro $n$ provocaram grandes diferenças nos valores calculados da evapotranspiração acumulada, como pode ser visto na Figura 14. A evapotranspiração acumulada de referência totalizou $30,51 \mathrm{~mm}$. Para as variações de $8,5,-5$ e $-8 \%$ no valor de referência do parâmetro n foram totalizados $19,64 \mathrm{~mm}, 19,76 \mathrm{~mm}, 37,09 \mathrm{e}$ $24,6 \mathrm{~mm}$, respectivamente. Os acréscimos em 8 e 5 $\%$ praticamente se sobrepuseram, e subestimaram os valores de EVP em todo o período. As reduções em 5 e $8 \%$ superestimou e subestimou os valores de EVP, respectivamente, a partir do quarto dia.

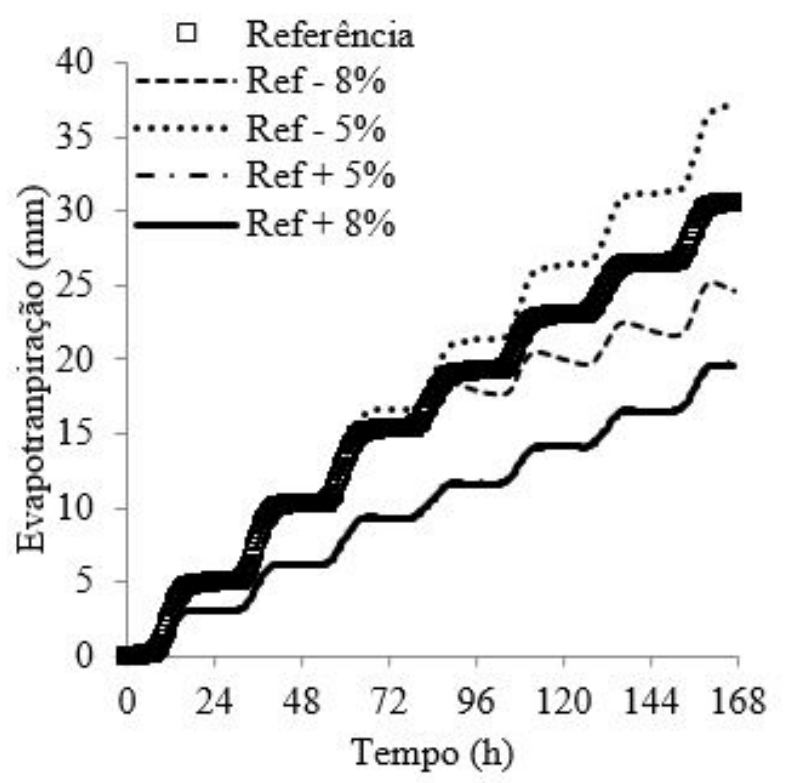

Figura 14. Evolução da evapotranspiração acumulada medida e calculados a partir das variações do $n$. 
As variações no parâmetro $\mathrm{n}$ provocaram diferenças nos valores calculados do fluxo de calor no solo, como pode ser visto na Figura 15. As maiores superestimativas foram provocadas pela redução e $8 \%$ no valor de referência do parâmetro $\mathrm{n}$, principalmente nos horários de pico. As superestimativas ocasionadas pela redução e $5 \%$ foram um pouco menores. Os aumentos nos valores de referência provocaram uma subestimativa nos valores calculados de G. No detalhe da Figura 16 observamos, em detalhe, de modo mais evidente, esses comportamentos.

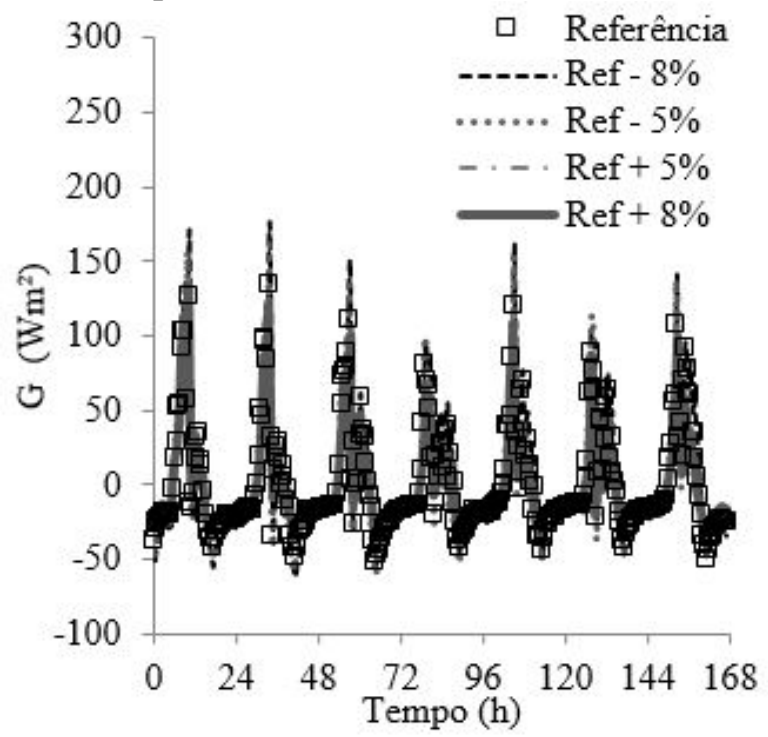

Figura 15. Evolução do fluxo de calor no solo medido e calculados a partir das variações do $n$.

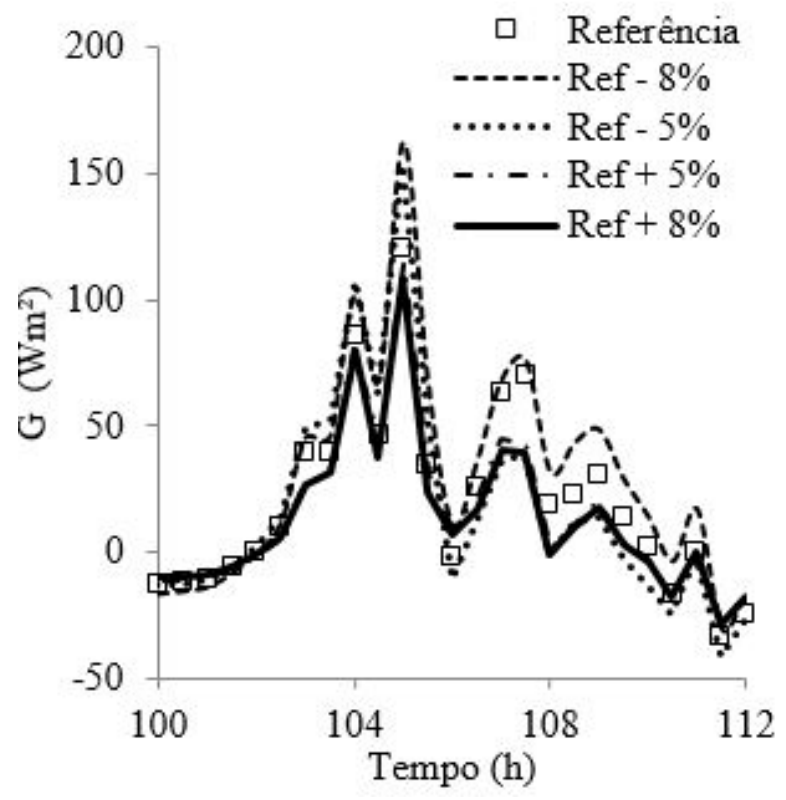

Figura 16. Detalhes da evolução do fluxo de calor no solo medido e calculados a partir das variações do n.

As variações no parâmetro $n$ provocaram grandes diferenças nos valores calculados do fluxo de calor latente, como pode ser visto na Figura 17. Observa-se que os valores do LE calculado com o valor de referência acrescido em $8 \%$ foram significantemente subestimados em todo o período analisado. Uma redução de $5 \%$ no valor de referência acarretou num grande aumento nos valores calculados pelo modelo SiSPAT, nos quatro últimos dias de simulação, sobretudo nos valores de pico. Nos três primeiros dias não ocorreram essa superestimativa. Os valores calculados para uma redução de $8 \%$ não superestimou os valores de pico, entretanto apresentou superestimativas dos valores negativos, no horário noturno, nos quatro últimos dias. Os valores de $\mathrm{H}$ calculados, após os acréscimos de 5 e $8 \%$ no valor de referência de n praticamente se sobrepuseram durante o período de estudo. Eles subestimaram os valores de referência de $\mathrm{H}$ durante todo o período.

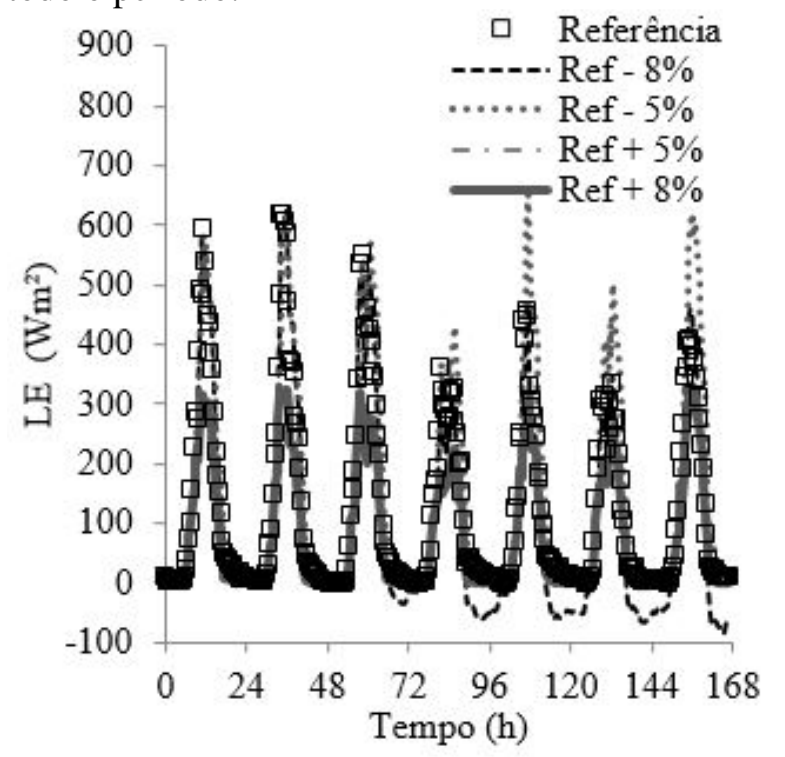

Figura 17. Evolução do fluxo de calor latente medido e calculado a partir das variações do $n$.

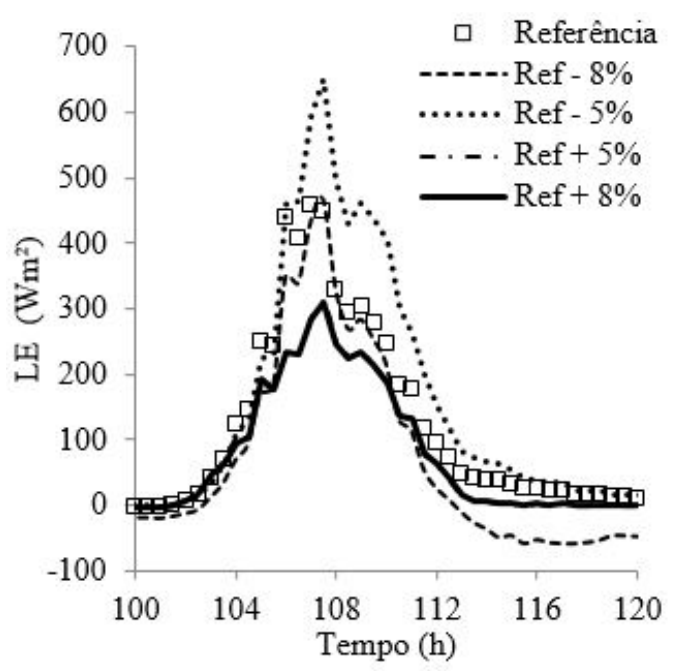

Figura 18. Detalhe da evolução do fluxo de calor latente medido e calculado a partir das variações do n. 
As variações no parâmetro $\mathrm{n}$ provocaram grandes diferenças nos valores calculados do fluxo de calor sensível, como pode ser visto na Figura 19. Os aumentos de $8 \%$ e $5 \%$ no valor de referência provocaram aumentos significativos nos valores calculados pelo SiSPAT, principalmente nos horários de pico. Estas superestimativas foram observadas em todo o período de análise. As reduções provocaram subestimativas nos valores calculados durante todo o período. No detalhe da Figura 20, observa-se que os valores calculados com o acréscimo de $5 \%$ e $8 \%$ praticamente se sobrepuseram. $\mathrm{O} \mathrm{H}$ calculado com o uma redução de $5 \%$ no valor de referência apresentaram grandes subestimativas.

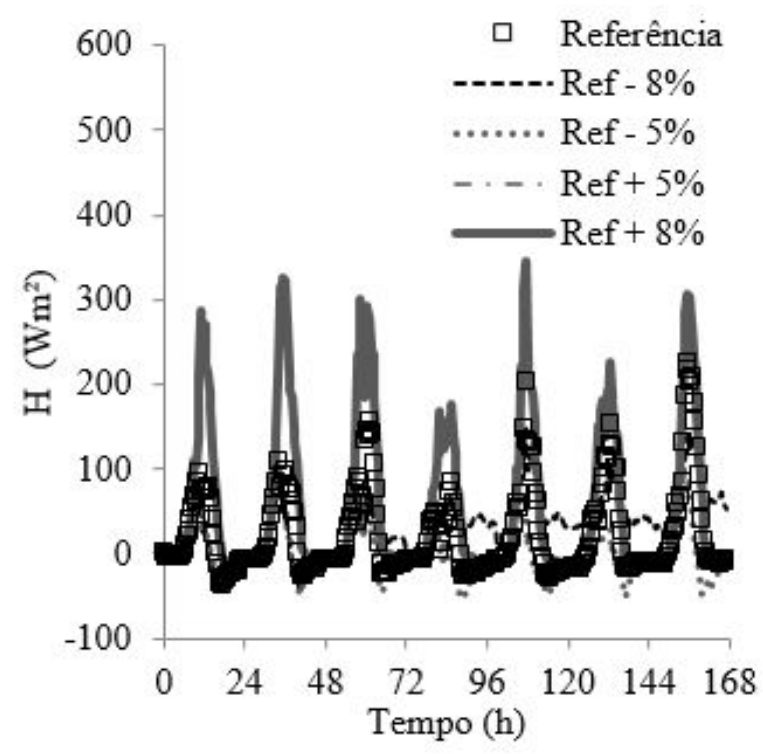

Figura 19. Evoluções dos fluxos de calor sensível medido e calculado a partir das variações do $n$.

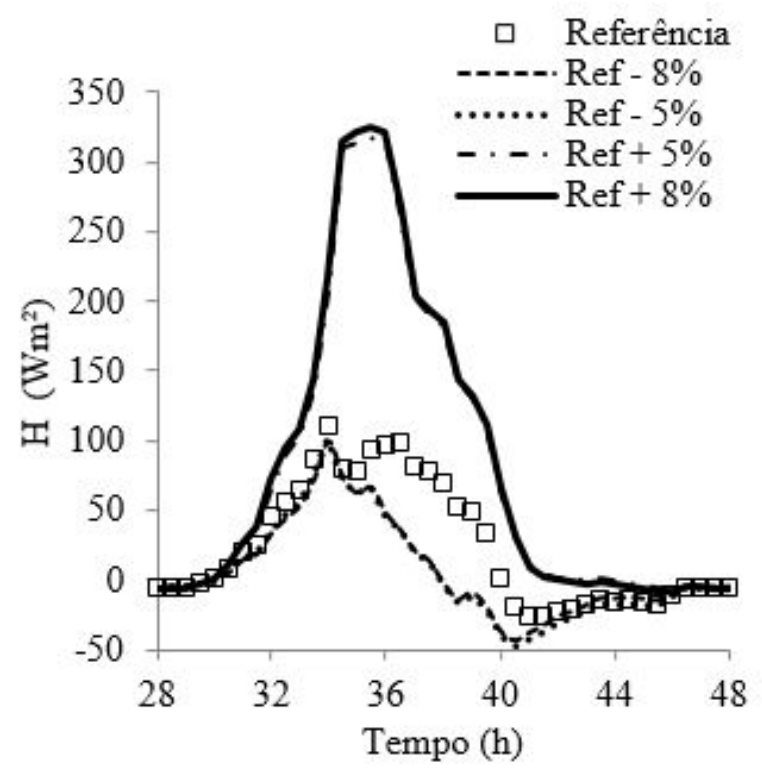

Figura 20. Detalhe da evoluções dos fluxos de calor sensível medido e calculado a partir das variações do $n$.
Nas Figuras 21 e 22 observa-se o efeito das variações dos parâmetros no cálculo do estoque de água no solo. O parâmetro "n" foi o que apresentou uma maior influência nos cálculos do estoque. Para nenhuma das variações nos parâmetros da vegetação, os valores calculados do estoque chegaram a $1 \%$ de variação.

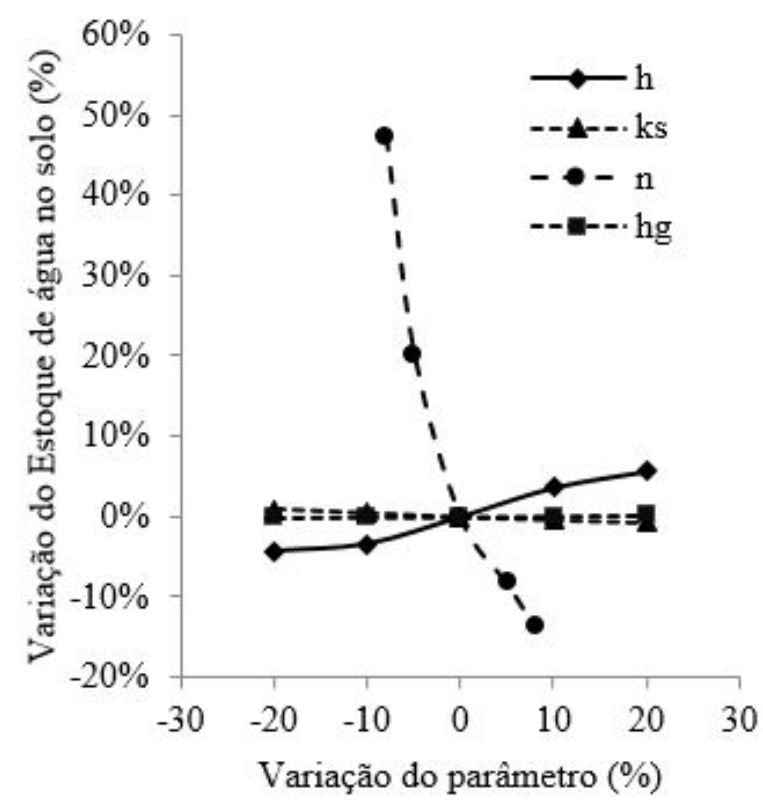

Figura 21. Variação percentual do estoque de água no solo como função variação dos parâmetros de entrada h, ks, n e hg.

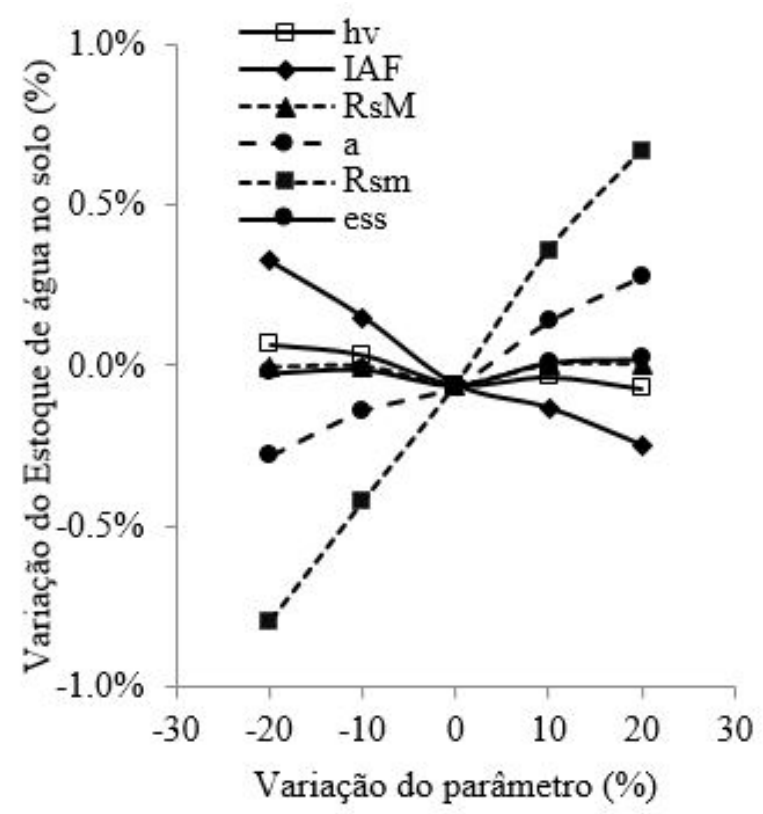

Figura 22. Variação percentual do estoque de água no solo como função variação dos parâmetros de entrada hv, IAF, RsM, a, Rsm e ess.

Nas Figuras de 23 a 28 observa-se o efeito das variações dos parâmetros no cálculo da evapotranspiração, evaporação e transpiração, respectivamente. Os parâmetros do solo 
apresentaram uma influência muito maior do que os parâmetros relativos a vegetação. Dentre os parâmetros do solo, o "n" e o " $\eta$ " foram os que mais influenciaram os três fluxos. Como era esperado, as maiores influências dos dados da vegetação foram encontradas no cálculo da transpiração, onde a resistência estomática mínima foi a que apresentou um maior destaque.

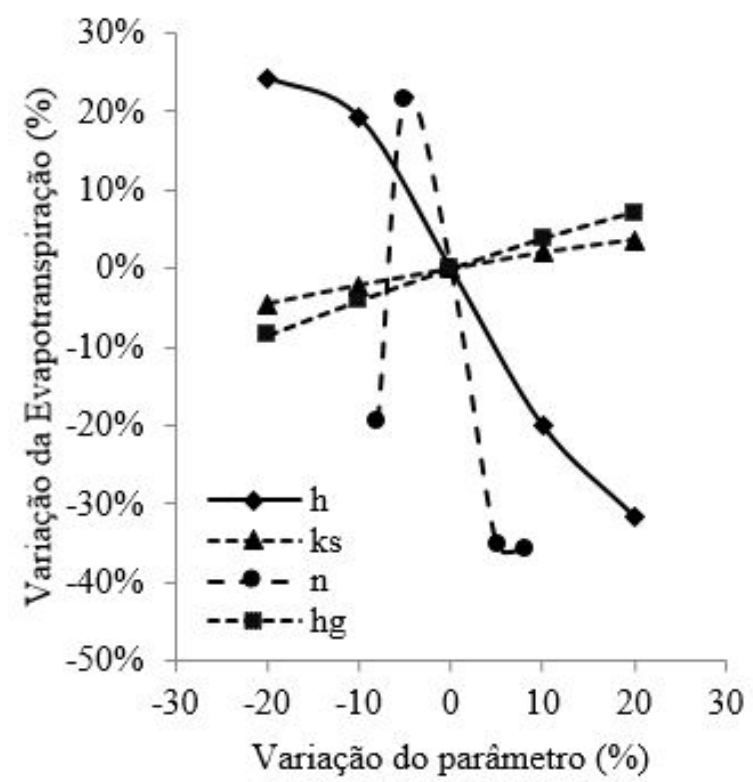

Figura 23. Variação percentual da evapotranspiração acumulada como função variação dos parâmetros de entrada h, ks, n e hg.

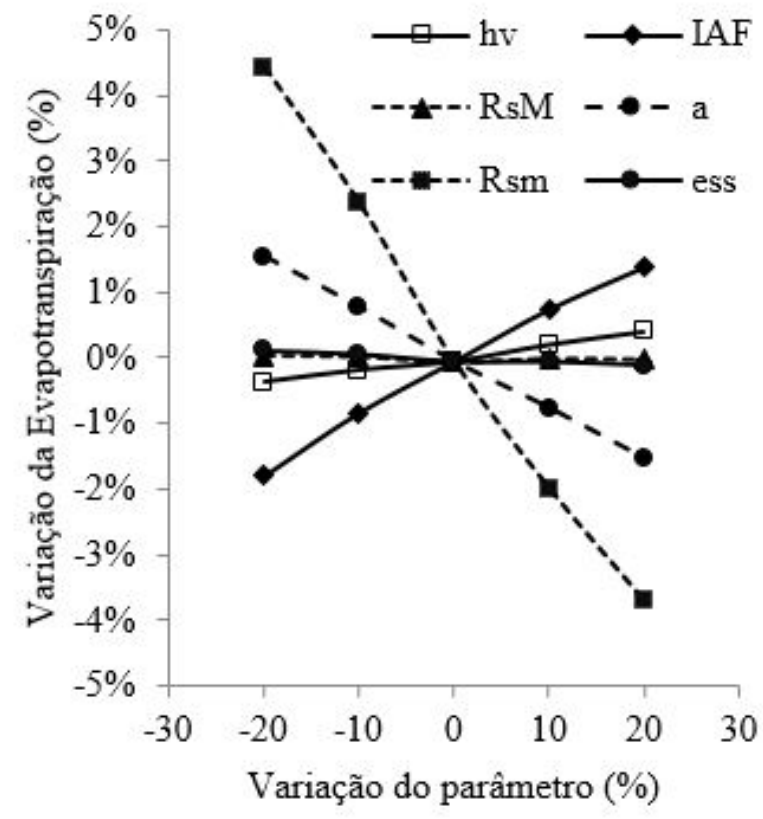

Figura 24. Variação percentual da evapotranspiração acumulada como função variação dos parâmetros de entrada hv, IAF, RsM, a, Rsm e ess.

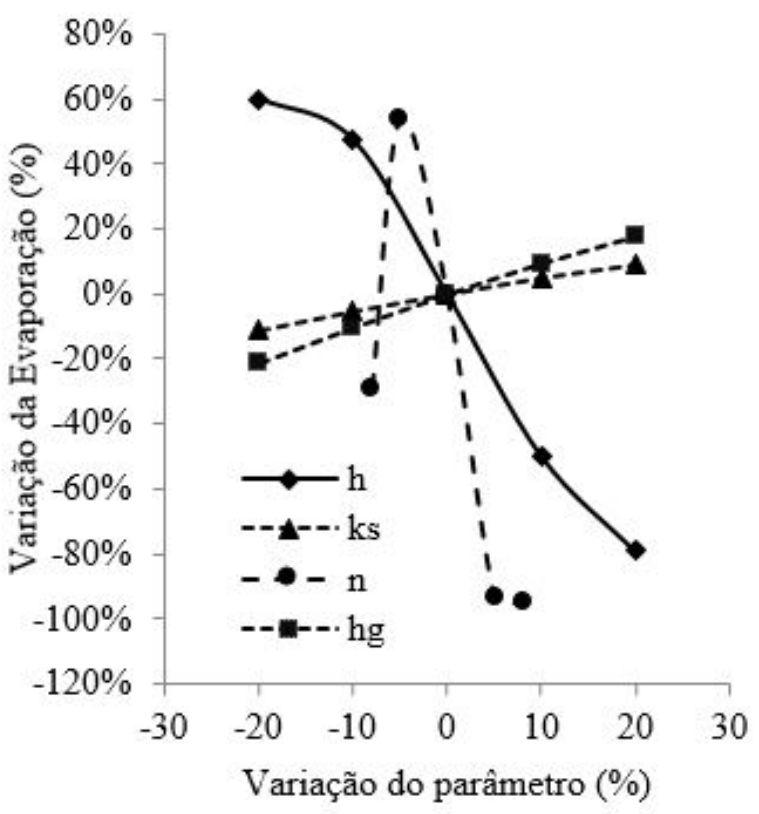

Figura 25. Variação percentual da evaporação acumulada como função variação dos parâmetros de entrada h, ks, n e hg.

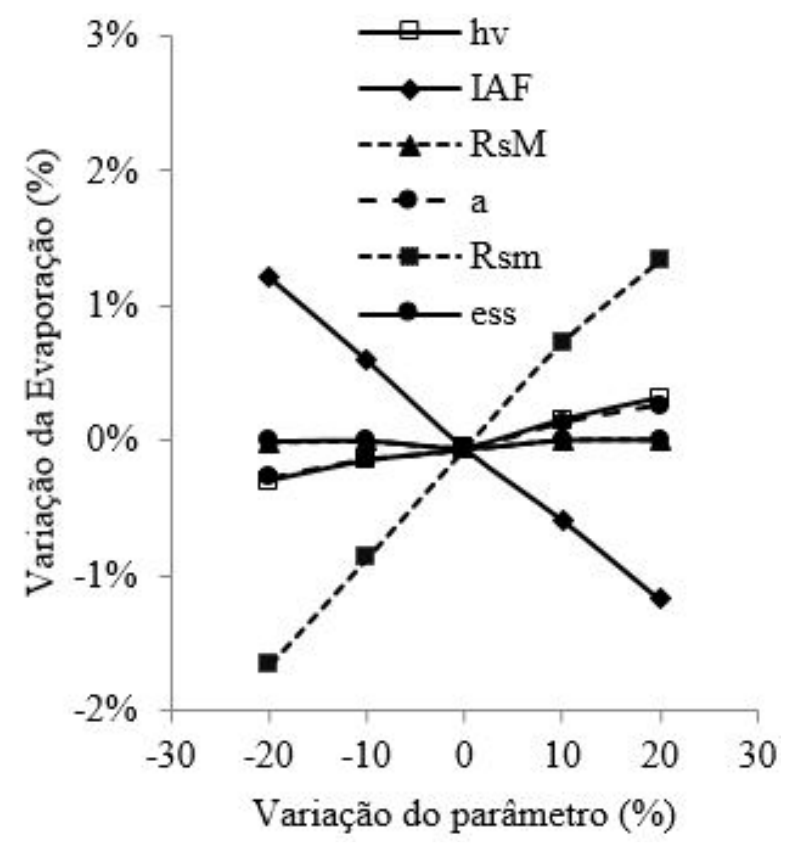

Figura 26. Variação percentual da evaporação acumulada como função variação dos parâmetros de entrada hv, IAF, RsM, a, Rsm e ess. 


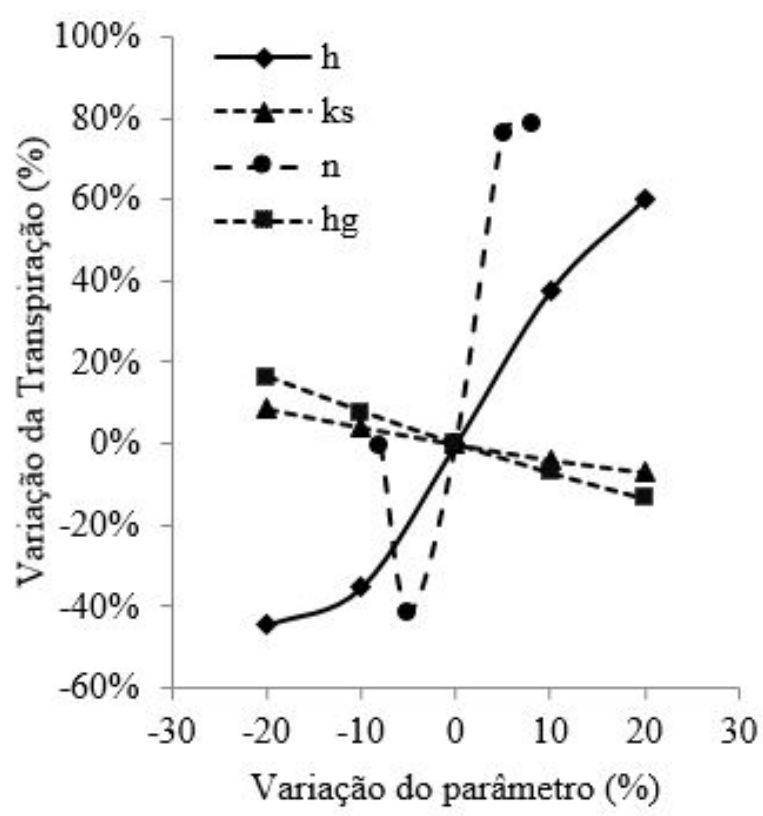

Figura 27. Variação percentual da transpiração acumulada como função variação dos parâmetros de entrada h, ks, n e hg.

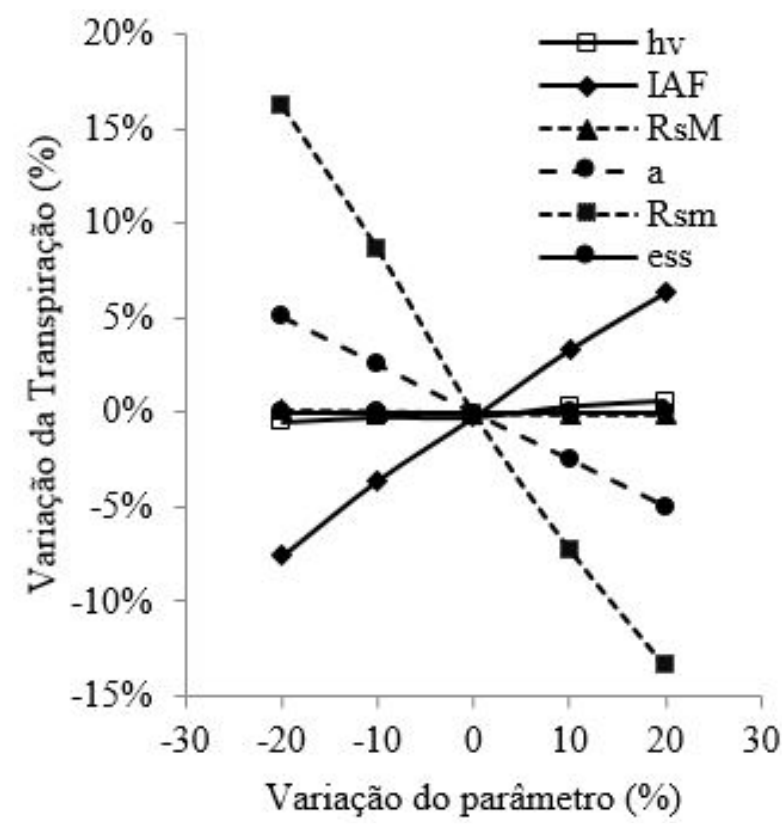

Figura 28. Variação percentual da transpiração acumulada como função variação dos parâmetros de entrada hv, IAF, RsM, a, Rsm e ess.

\section{Conclusão}

O modelo SiSPAT não se mostrou sensível as variações do parâmetro $g$ da função de estresse, do albedo e da emissividade da vegetação. Apenas nas reduções dos valores de referência do potencial foliar crítico e da resistência total da planta o modelo apresentou sensibilidade, e de forma discreta.

Dos parâmetros relativos à vegetação, o índice de área foliar e a resistência estomática mínima foram os que apresentaram maior influência nos valores calculados pelo modelo
SiSPAT. O modelo mostrou-se mais sensível as variações nos parâmetros relativos ao solo.

O modelo SiSPAT mostrou-se muito sensível as variações dos parâmetros do solo, principalmente ao parâmetro n. Sendo o fluxo de calor sensível o dado de saída aqui analisado o mais sensível.

\section{Agradecimentos}

Os autores agradecem ao Conselho Nacional de Pesquisa CNPq o apoio financeiro (Projetos: 475094/2009-3; 448504/2014-6; 307641/2013-9, 312218/2013-3) e à Bolsa de Produtividade de Antonino, A.C.D.

\section{Referências}

AMAZONAS, I. B.; ANTONINO, A. C. D. ; SOARES, W. .; LIMA, J. R. S.MONTENEGRO, S. M. G. L. 2015. Estimativa da evaporação usando o modelo sispat em propriedade particular no município de São João - Pernambuco / Brasil. Revista de Geografia, v.32, n.2, p.63-76.

ANTONINO, A. C. D. 1992. Modélisation des transferts de masse et de chaleur dans le système sol-plante-atmosphère. Influence de la variabilité spatiale des caractéristiques hydrodynamiques du sol. 195 p. Tese de Doutorado, Universidade Joseph Fourier, Grenoble, França.

BALDOCHI, D. D.; VERMA, S. B.; ROSENBERG, D. 1981. Mass and energy exchange of a soybean canopy under various environmental conditions. Agronomics Journal, v.73, p.706-710,

BORMANN, H. 2008. Sensitivity of a soilvegetation-atmosphere transfer scheme to input data resolution end data classification. Journal of Hydrology, v.351, p.154-169.

BOULET, G.; KALMAB, J. D.; BRAUDA, I.; VAUCLINA, M. 1999. An assessment of effective land surface parameterization in regional-scale water balance studies. Journal of Hydrology, v.217, p.225-238,

BRAUD I. 1998. Spatial variability of surface properties and estimation of surface fluxes of a savannah. Agricultural and Forest Meteorology, v.89, p.15-44,

BRAUD, I., 2000. SiSPAT version 3.0, User's manual, Septembe, 83 p., available from LTHE, BP 53, 38041 Grenoble Cedex 9, France. 
BRAUD, I.; DANTAS-ANTONINO, A. C.; VAUCLIN, M. 1995b. A stochastic approach to studying the influence of the spatial variability of soil hydraulic properties on surface fluxes, temperature and humidity. Journal of Hydrology, v.165, p.283-310.

BRAUD, I.; DANTAS-ANTONINO, A. C.; VAUCLIN,O. M. O.; THONY, J. L. O.; RUELLE, P. 1995a. A simple soil-plant-atmosphere transfer model (SISPAT) development and field verification. Journal of Hydrology, v.166, p.213250.

BRAUD, I.; TILMANT, F. SAMIE, R. GOFF, I. L. 2013. Assessment of the SiSPAT SVAT Model for Irrigation Estimation in South-East France. Procedia Environmental Sciences, v.13, p.747-756.

BROOKS, R. H.; COREY, A. T. 1964. Hydraulic properties of porous media. Hydrol. Pap. 3, Colo. State Univ., Fort Collins.

BRUTSAERT, W. 1982. Evaporation into the Atmosphere. D. Reidel, Dordrecht, 299 p.

CASTRILLO, L. S.; LIMA, F. R. A.; BALIÑO, J. L. 2004. Aplicações de métodos perturbativos para análise de sensibilidade em escoamentos bifásicos. In.: Mecânica Computacional, v.XXIII, p.27592778 .

CELIA, M. A.; BOULOULAS, E. T.; ZARBA, R. L. 1990. A general mass conservative numerical solution for the unsaturated flow equation. Water Resources Research, v.26, p.1483-1496.

CHAPELLE, A.; MENESGUEN, A.; DESLOUSPAOLI, J. M.; SOUCHU, P.; MAZOUNI, N.; VAQUER, A.; MILLET, B. 2000. Modelling nitrogen, primary production and oxygen in a Mediterranean Lagoon. Impact of oysters farming and inputs from the watershed. Ecological Modeling, v.127, p.161-181.

CUNHA, A. P. M. A. 2007. Calibração do "Simplified Simple Biosphere Model - Ssib" para o bioma caatinga do Nordeste brasileiro, Dissertação de Mestrado, 134 p.

DEARDOFF, J.W. 1978. Efficient prediction of ground surface temperature and moisture with inclusion of a layer of vegetation. J. Geophys. Res., v.83, p.1889-1903.

DICKINSON, R. E.; HENDERSON-SELLERS, A.; KENNEDY, P. J.; WILSON, M. F. 1986.
Biosphere Atmosphere Transfer Scheme (BATS) for the NCAR Community Climate. Model. NCAR, USA.

FARIAS, S. E. M.; MEIRELLES, M. L. ; FRANCO, A. C.; NOGUEIRA, J. L. M.; GUERRA, A. F. E MANZI, A. O. 2004. Balanço de energia em cultivo de milho no cerrado. Revista Brasileira de Agrometeorologia, v.12, n.2, p.227233.

FEDERER, C. P. 1979. A soil-plant-atmosphere model for transpiration and availability of soil water. Water Resources Research, v.15, n.3, p.555562.

KAHAN, D.; XUE, Y.; ALLEN, S. 2006. The impact of vegetation/soil parameters in simulations of surface energy and water balance in the semiarid Sahel area: a case study using SEBEX and HAPEX-Sahel data. Journal of Hydrology, v.320, n.1-2, p.238-259.

KANEMASU, E. T. ROSENTHAL, U. D., RANEY, R. J.; STONE, L. R. 1977. Evaluation of an evaporation model for corn. Agron. J., v.69, p.461-464.

MONIN, A. S.; OBUKHOV, A. M. 1954. Basic relationships of turbulent mixing in the surface layer of the atmosphere. Doklady Akademii Nauk SSSR, v.151, n.24, p.163-187.

NECES, D. G.; CUNHA, A. C.; SOUZA, E. B.; BARRETO, N. J. C. 2011. Modelagem climática regional durante dois anos de extremos de Precipitação sobre o estado do amapá: teste de sensibilidade aos Esquemas convectivos. Revista Brasileira de Meteorologia, v.26, n.4, p.569-578.

PASSERAT DE SILANS, A. M. B.; BRUCKLER, L.; THONY, J. L.; VAUCLIN, M. 1989. Numerical modeling of coupled heat and water flows during drying in a stratified bare soil. Comparison with field observations. J. Hydrol., v.105, p.109-138.

PAULSON, C. A. 1970. The mathematical representation of wind speed and temperature profiles in the unstable atmospheric surface layer. Journal of Applied Meteorology, v.9, p.857-861.

PENG, J. F.; WANG, B. Z.; SONGA, Y. H.; YUANA, P. 2007. Modeling N transformation and removal in a duckweed pond: Model development and calibration, v.206, n.1-2, p.147-152. 
PEREIRA, G.; SILVA, M. E. S.; MORAES, E. C.; SHIMABUKURO, Y. E.; CARDOZO, F. S.; SILVA, F. B.; ARAI, E. 2010. Impactos climáticos das áreas alagadas no Bioma Pantanal. Embrapa Informática Agropecuária/INPE, pp.190-199.

RAUDKIVI, A. J. 1979. Hydrology: An advanced introduction to hydrological processes and modelling. Ed by Pergamon Press, London/UK, $479 \mathrm{p}$.

SILVA, A. P.; DUARTE, C. S.; OLIVEIRA, D. B. C.; HOLANDA, M. A. C. R.; NETO, N. A. A.; SOARES, W. A. 2014. Diferentes aspectos do uso de modelos computacionais aplicados às ciências ambientais. Diálogos: Revista de Estudos Culturais e da Contemporaneidade, v.12, p.315-342.

SOARES, W. A. 2009. Fluxos de água e de energia em feijão macassar e mamona no nordeste do Brasil. 167 p. Tese de Doutorado, Universidade Federal de Pernambuco, Pernambuco, Brasil.
SOARES, W. A.; ANTONINO, A. C. D.; LIMA, JOSÉ R. DE S.; SOUZA, EDUARDO SOARES DE; MONTENRGRO, S. M. G. L.; LIRA, CARLOS A. B. DE O. 2013. Simulação dos fluxos de água e de energia na microbacia hidrográfica da represa Vaca Brava no Brejo Paraibano.. Revista Brasileira de Recursos Hídricos, v.18, p.185-196.

VAN GENUCHTEN, M. Th. 1980. A closed-form equation for predicting the hydraulic conductivity of unsatured soils. Soil Science Society American of Journal, v.44, p.892-898.

XUE, Y.; BASTABLE, H. G.; DIRMEYER, P. A.; SELLERS, P. J. 1996. Sensitivity of Simulated Surface Fluxes to Changes in Land Surface Parameterizations-A Study Using ABRACOS Data. Journal of Applied Meteorology, v.35, p.386400. 